\title{
CENEPA: LA ÚLTIMA GUERRA TERRITORIAL
}

\author{
"Para que el poder fluya, el mundo debe estar libre de trabas, barreras, fronteras fortificadas y controles. \\ Cualquier trama densa de nexos y relaciones sociales, y particularmente una red estrecha con base territorial, \\ implica un obstáculo que debe ser eliminado.” (Bauman, Modernidad líquida 2004, 17)
}

\section{RESUMEN}

Dr. Napoleón Saltos,Mgs. ${ }^{1}$

Al conmemorar los 25 años de la Guerra del Cenepa, el artículo aborda el análisis del sentido del acontecimiento, a partir de su genealogía, la pregunta sobre los procesos que cierra y los procesos que abre. La tesis central es que la Guerra del Cenepa es la última guerra territorial, el cierre victorioso de una larga historia traumática de límites. Y, a la vez, abre el paso de la frontera Sur a la Frontera Norte, el paso de las fronteras territoriales a las fronteras globales, el paso a los cambios de la modernidad "líquida". El cambio político clave es el debilitamiento de los Estados-nacionales, sometidos a un doble asedio: desde afuera, el asedio del poder transnacional, que ha instituido una nueva Doctrina de Seguridad Nacional, para resolver la guerra contra el nuevo enemigo global, post Guerra-Fría, el terrorismo y el narcotráfico, bajo la tutela de los Estados fuertes y el poder americano. Y un asedio desde adentro, las luchas sociales en medio de la superposición de diversas soberanías y violencias, en el marco del Estado Plurinacional. Las Fuerzas Armadas están ante el interrogante de su papel en las condiciones de la democracia en crisis y de los cambios globales; una disyuntiva entre la subordinación a una estrategia que restablece los postulados de las doctrinas de seguridad nacional, para enfrentar la subversión interna; o que busca la salida en la articulación con las demandas sociales. La conmemoración de los 25 años de la Guerra del Cenepa es una oportunidad para traer, en espiral, la memoria del pasado al presente, para responder a las preguntas actuales.

Palabras claves: Guerra del Cenepa, Fuerzas Armadas, Estado nacional, Soberanía, Violencia, Cambios globales.

\begin{abstract}
In the commemoration of the 25 years of the Cenepa War, the article analyzes the meaning of the event, based on its genealogy, the question about the processes that it closes and the processes that it opens. The central thesis is that the Cenepa War is the last territorial war, the victorious closure of a long traumatic history of boundaries. And, at the same time, it opens the passage from tee South border to the North border, the passage from territorial borders, the step to the changes of "liquid" modernity. The principal political change is the weakening of national states, subject to a double siege: from outside, the siege of transnational power, which has instituted a new National Security Doctrine, to resolve the war against the new global enemy, post Cool-War, terrorism and drug trafficking, under the tutelage of the strong states and American power. And a siege from interiority, the social struggles amid the superposition of various sovereignty and violence, within the framework of the Plurinational State. The Armed Forces are facing the question about of their role in the conditions of democracy in crisis and of global changes. A disjunctive between the subordination to a strategy that restores the postulates of national security doctrines, to confront internal subversion; or that looks for the exit in the articulation with the social demands. The commemoration of the 25 years of the Cenepa War is an opportunity to bring, in a spiral, the memory of the past to the present, to answer the current questions.
\end{abstract}

Key words: Cenepa War, Armed Forces, National State, Sovereignty, Violence, Global changes.

\footnotetext{
1 wnsaltosg@yahoo.es

INVESTIGADOR INDEPENDIENTE
} 


\section{Introducción}

Conmemoramos los 25 años de la Guerra del Cenepa. Es una oportunidad para reflexionar sobre el proceso de las Fuerzas Armadas ante los cambios que se han producido, tanto a nivel interno como global.

\section{Lecturas}

Un hecho se puede leer desde atrás, del pasado al presente, en términos historicistas, y se produce la descripción celebratoria de la memoria. O se puede leer desde el presente, para producir la genealogía del acontecimiento ${ }^{2}$, a partir de la pregunta sobre los procesos que cierra y los procesos que abre.

Averiguar "el momento constitutivo, el momento fundacional de un evento histórico. En palabras de Zavaleta, el momento constitutivo se asienta en el interrogante: "(...) de dónde viene este modo de ser de las cosas: las razones originarias" (Zavaleta 1990, 80)) (...); allí se encuentran los elementos que, desarrollándose, finalmente darán forma a ese modo de ser." (Accossatto 2017, 171)

La guerra del Alto Cenepa es la última guerra territorial del Estado-nacional ecuatoriano, y, a la vez, abre la incorporación al nuevo orden geopolítico; el desplazamiento desde el ordenamiento en la frontera Sur en el enfrentamiento al "enemigo del Sur", al dislocamiento de fuerzas en la frontera Norte, en un reordenamiento del carácter de la seguridad desde una nueva lógica geopolítica, en el enfrentamiento a las nuevas amenazas globales. Pero este cierre no se realiza desde la lógica de los Estados-nacionales, sino desde el protagonismo de los garantes, el juego de fuerzas globales, encabezadas por el poder norteamericano.

\section{La genealogía}

La genealogía de la Guerra del Cenepa parte de la identidad del Ecuador como una "nación en ciernes", que no termina por definir sus límites territoriales desde su propia constitución. Conflictos y guerras con el Perú que encuentran su identidad patriótica en el discurso de "la herida abierta", a partir de la Guerra del 41. Un juego de espejos que se reactiva periódicamente, de acuerdo a los tiempos de las políticas locales de los dos países confrontados y los condicionamientos de los poderes globales.

Si bien es un proceso largo, recogido en una traumática "historia de límites" que muestra el cercenamiento progresivo del territorio nacional, la genealogía de la Guerra del Cenepa se puede encontrar más directamente en las guerras del 41 y del 81 .

"La guerra del 41 nos mostró la imagen de un pueblo vencido, un pueblo de perdedores. Sus desastrosos resultados, para un país que a lo largo de su vida republicana había sido testigo permanente de la pérdida de su territorio, implicó para la conciencia y sentimiento de los ecuatorianos la mutilación de una parte de sí mismos." La derrota del 41 y la firma del Protocolo del Río de Janeiro fueron "el hecho histórico (...) más traumático para el país de todo del siglo XX." (Silva 2005, 90)

La reacción de la sociedad fue no aceptar el Protocolo de Río de Janeiro. La identidad nacional se trazó a partir de este sentimiento. "La revolución de mayo del 44, "La Gloriosa", sería la primera respuesta masiva de la sociedad a una clase política a la que estigmatizó implacablemente con el adjetivo de "traidora". Más tarde, en los años 60, esa misma clase política capturaría la inconformidad y la resistencia de la sociedad, al lanzar por medio de Velasco Ibarra la tesis de la "Nulidad del Protocolo de Río de Janeiro".” (Silva 2005, 89-90)

Sobre todo, la identidad de las Fuerzas Armadas y el dislocamiento estratégico y geográfico de fuerzas se organizaron a partir de este imaginario, el enfrentamiento al "enemigo del Sur", con un vago y difuso sentimiento antiimperialista, ante las imposiciones de los garantes y, en particular, de los Estados Unidos, por sus intereses geopolíticos.

En los 60 y 70 se complementarían con las orientaciones de la Doctrina de Seguridad Nacional, que ubicaron a la subversión, el enemigo interno, como la amenaza principal; por lo cual el dislocamiento de fuerzas colocó los cuarteles a la entrada de las ciudades para evitar la entrada de la subversión desde el campo.

La guerra de Paquisha, en 1981, refuerza el imaginario defensivo en el Ecuador. En "esta jornada de lucha que evitó que el Perú consumase sus pretensiones expansionistas, mucho tuvo que ver la decidida acción gubernamental dirigida por el presidente Jaime Roldós Aguilera, que incitó a la Organización de Estados Americanos que interviniera conciliadoramente en el conflicto." (Academia Nacional de Historia Militar del Ecuador 2020, 38)

El conflicto del 81 tuvo un fuerte impacto económico, que impulsó el viraje desde el modelo desarrollista de la década de los 70, hacia el modelo de mercado: "El conflicto fronterizo con el Perú de 1981, al tiempo que agudiza los inveterados problemas de la socioeconomía ecuatoriana, marca el punto de flexión del proyecto reformista y redistributivista de nuestra burguesía de nuevo cuño. (...) A partir de la Guerra de Paquisha la balanza se inclina decididamente al enfoque (...) del modelo exportador-importador propugnado por el FMI y el Banco Mundial” (Báez 2003, 198)

2 " [No hay] nada que se parezca a la evolución de una especie, al destino de un pueblo. Seguir la filial compleja de la procedencia es, por el contrario, mantener lo que pasó en la dispersión que le es propia (...); es descubrir que en la raíz de lo que conocemos y de lo que somos no están en absoluto la verdad y el ser, sino la exterioridad del accidente.” (Foucault 1994, 141) 


\section{El acontecimiento}

La participación de las Fuerzas Armadas en el Gobierno de 1972 a 1978, había distraído a la institución de su misión fundamental, la defensa de la soberanía nacional. Después del revés del 81 , una reacción inmediata fue el refuerzo de la orientación profesional dentro de las filas castrenses y el planteamiento de la necesidad de prepararse con anticipación a un nuevo conflicto.

A raíz del Conflicto de 1981, quedó entre los militares un sentimiento de frustración: "Siempre me pareció que todos los combatientes quedamos marcados por no haber conseguido los objetivos propuestos, a pesar de que se ejecutaron con relativo éxito todas las operaciones y se tuvieron buenos mandos; pero la decisión política echó al traste todo el esfuerzo militar y como siempre, los países garantes dieron la razón al Estado Peruano." (Vasco 2019)

Se desarrolla una estrategia planificada: en el campo organizativo, articulación de las diferentes ramas, creación de nuevas unidades; en el campo técnico la modernización del armamento; y en la preparación y entrenamiento del personal militar, con tropas especializadas. Esta planificación tenía el propósito de preparar las FF.AA. para el caso de producirse otro conflicto, estar listos para enfrentarlo con relativo éxito y evitar que se produzca las negativas experiencias del pasado.

Un equipo de militares-intelectuales, José Gallardo, Carlo Magno Andrade, Miguel Iturralde y Paco Moncayo, elaboran una estrategia que integra diversas visiones teórico-prácticas, adaptándolas a las condiciones concretas del país, para enfrentar a un enemigo más poderoso. Es un momento que rompe la continuidad de la reproducción de estrategias externas, y se da paso a la innovación de la estrategia militar de acuerdo a las condiciones especiales del enfrentamiento con el Perú.

Tres elementos claves: la adaptación al terreno, para una ventaja operativa; la alianza con la población, sobre todo nativa, en particular en la Amazonía; la estrategia de guerra de guerrillas en el suelo, "que permita aplicar una nueva doctrina de guerra no convencional, en las operaciones que se desarrollan en un medio selvático" (Academia Nacional de Historia Militar del Ecuador 2020), con apoyo coordinado aéreo y de defensa antiárea.

Las Fuerzas Armadas se reorganizan bajo la misión de la defensa de la soberanía y la recuperación de la dignidad nacional, después de una historia de derrotas. Las nuevas estrategias y planes de guerra se elaboran y practican en los Institutos de formación de las FF. AA., particularmente en las Academias de Guerra del Ejército, de la Fuerza Aérea y Naval. Se sigue un plan trazado. Este espíritu atraviesa al conjunto de la institución armada.

El General José Gallardo, Comandante de las Fuerzas Armadas durante el conflicto, al analizar "La conducción político-militar de la Guerra del Cenepa", señala: "En conocimiento de lo relatado, quienes ingresaban a las Fuerzas Armadas los hacía (sic) imbuidos de la firme decisión de impedir que esa triste historia se repitiera." Y concluye, "para 1994 las Fuerzas Armadas estaban entrenadas para luchar en cualquier escenario e imbuidas de un espíritu heroico, jerarquizadas, disciplinadas y cohesionadas." (Academia Nacional de Historia Militar del Ecuador 2020, 66 y 68)

Este espíritu se confirma en las memorias del acontecimiento. El General Carlos Patricio Vasco, Comandante de la Brigada Especial de combate Eloy Alfaro, al relatar "La logística de la Guerra del Cenepa", señala "las decisiones (...) permitieron que la Brigada Especial de Combate Eloy Alfaro cumpla la misión y sea parte de la estructura militar que recuperó el honor y la dignidad nacional con un mínimo de pérdidas." Analiza el papel de la logística y de las líneas de abastecimiento, para garantizar el resultado exitoso. Subraya: Durante la Guerra del Cenepa, "se materializan las aptitudes, deseos y aspiraciones de una generación que se preparó con dedicación para recuperar el honor nacional, después de los aciagos resultados del año 1981. El permanente y meticuloso entrenamiento que se realizó desde esa fecha permitió que el personal en todos los niveles jerárquicos garantice la eficiencia operativa de cada especialidad." (Vasco 2019, 9 y 12)

Este espíritu penetra también a la sociedad ecuatoriana. El largo relato de la "historia de límites" muestra un país humillado y el cercenamiento progresivo de su territorio. La educación cívica crea un imaginario de recuperación de la dignidad y el honor nacional. El papel de la sociedad es clave para el resultado del conflicto del Cenepa, no sólo como apoyo, sino como recurso estratégico operativo.

El General Vasco, en el relato de "la logística de la guerra del Cenepa", expresa su agradecimiento “a la población de Gualaquiza que nos acogió con mucho cariño y nos ayudó a resolver los problemas que se presentaron en el área de retaguardia; especialmente a las señoras que trabajaron todos los días en la preparación de las raciones que alimentaron a los valerosos soldados en combate." Recuerda "el espíritu cívico y patriótico del pueblo ecuatoriano, particularmente el de los niños escolares y jóvenes de educación media, se sintió con tanta fuerza en el frente de combate, que comprometió más a los soldados que estábamos defendiendo la heredad territorial.” (Vasco 2019, 9 y 51)

Un signo de la alianza con la población nativa es la creación de la Escuela de Iwias Coronel Gonzalo Barragán: "Con el fin de aprovechar los talentos étnicos propios de convivir en el ambiente selvático de los nativos y colonos, fue instaurada la Escuela de Iwias en 1982, para crear posteriormente las especialidades en selva con nombres propios de sus lenguas. Esta escuela es el 
ejemplo más interesante, a nivel mundial, de la fusión de las culturas amazónicas con la cultura militar" (Academia Nacional de Historia Militar del Ecuador 2020)

A diferencia de lo sucedido en 1941 y 1981, en que el Ecuador respondió a la iniciativa ofensiva del Perú, en la Guerra del Cenepa, las tropas ecuatorianas cuentan con una estrategia definida. Responden rápidamente a la invasión peruana a territorio ecuatoriano, aceptado previamente por los propios militares peruanos, aunque no estaba delimitado oficialmente. La estrategia peruana tradicional había sido invadir de hecho, luego consolidar su presencia, dependiendo de la reacción militar ecuatoriana, que anteriormente era muy débil. En esta ocasión, cambiaron las circunstancias, las fuerzas militares ecuatorianas reaccionaron oportunamente, pasando a tomar la iniciativa respecto al momento y al terreno.

El inicio de la guerra fue el resultado de la crónica de un conflicto anunciado: a partir de 1990, el conflicto en torno al Puesto de Vigilancia Pachacutec, implantado por el Perú en territorio en disputa, y luego el incumplimiento por parte del Perú del "Pacto de Caballeros" firmado el 24 de agosto de 1991, para remover el Puesto Pachacutec al Puesto Chiqueiza o a otro lugar equivalente, alertó al Ecuador sobre las intenciones del Perú, tanto más que el Presidente Peruano, Alberto Fujimori, mantenía públicamente el discurso de que "no habrá retroceso de ninguna especie". (Academia Nacional de Historia Militar del Ecuador 2020)

El Perú estaba debilitado por el conflicto interno y por el desgaste del régimen fujimorista, que se encontraba en campaña para la reelección, y que trató de utilizar el conflicto como propaganda para un respaldo "nacionalista". Si bien cuantitativamente se mantenía la superioridad armamentista del Perú, Ecuador había logrado niveles de modernización en todas las ramas, sobre todo en la Fuerza Aérea y en la defensa antiárea, que le daban una relativa superioridad táctica.

La orientación apuntó a una guerra localizada en el Alto Cenepa. Un conflicto más ampliado era difícil para el Ecuador. El relato de la nulidad del Protocolo de Río de Janeiro se había condensado en la tesis de la inejecutabilidad del Protocolo, por la ausencia de la divisoria de aguas entre el Zamora y el Santiago, ya que el Río Cenepa no era un mero afluente menor, sino un sistema hidrográfico independiente.

La zona en disputa estaba en torno a la Cordillera del Cóndor, convertida en territorio estratégico no sólo de límite territorial, sino también de rol económico por la presencia de reservas mineras. "El Ejército peruano (...) conocía también de la inmensa riqueza aurífera y de otros metales además del petróleo que se acumula en esa zona en cantidades significativas. (Academia Nacional de Historia Militar del Ecuador 2020, 32)
El Ecuador contaba con algunas ventajas estratégicas: líneas más cortas de abastecimiento y comunicación, preparación de tropas especializadas para el combate en selva, alianza con los pueblos indígenas shuar, ubicación en la parte superior de la Cordillera.

La Guerra del Cenepa es la última guerra territorial, pero aborda algunas estrategias de las nuevas guerras totales, sobre todo respecto al papel activo de la opinión pública y la propaganda a nivel interno y externo. A pesar del desgaste del Gobierno de Sixto Durán, durante el conflicto se logra concentrar la voluntad nacional en torno a la defensa de la Patria, la consigna fue "Ni un paso atrás". La disputa de la opinión pública se dio también a nivel internacional.

El teatro de disputa de la Guerra del Cenepa se concentró en 40 kilómetros cuadrados, en el lado oriental de la Cordillera del Cóndor, ocupado por las Fuerzas Armadas Ecuatorianas. El argumento apuntaba a convertir la cumbre de la Cordillera del Cóndor en la nueva delimitación.

Desde 1994, el Ecuador despliega los puestos avanzados Cueva de los Tayos, Base Sur y Twintza, en la zona sin delimitación. El conflicto se inicia el 26 de enero de 1995, cuando una Patrulla peruana intentaba construir un helipuerto en la quebrada Fashin, en la cabecera del Río Cenepa. El ataque ecuatoriano por tierra, con apoyo de helicópteros de la FAE, logra tomar la zona, que es denominada Base Norte. Las fuerzas peruanas se movilizan y atacan la Base de Coangos el 29 de enero, y luego se amplían a las operaciones a toda la zona.

Tiwintza se convierte en el símbolo de las batallas por el control territorial. La infantería y los soldados de fuerzas especiales del Ecuador, al mando de los coroneles Luis Hernández y Luis Aguas, en coordinación con el General Paco Moncayo en Patuca, desalojaron a los soldados peruanos del territorio defendido por el Ecuador.

El triunfo, y sobre todo la imagen de la victoria, se forjó en los cielos y en la tierra. El 10 de enero, "las alas ecuatorianas se adornaron con los laureles de la victoria, al derribar a tres aviones enemigos que bombardeaban nuestras posiciones." (Moncayo 1995) La población, desde abajo fue testigo del estruendo del derribo de los aviones enemigos, y pudo festejar la victoria. En la disputa de sentido, esa era la prueba del triunfo, junto a la disputa, material y virtual, sobre la ocupación de Twinza.

El 17 de febrero se firma la Declaración de Paz de Itamaraty (Brasil) que dispone la separación de las fuerzas beligerantes, bajo la vigilancia de los garantes. El 22 de febrero es el día más conflictivo, con numerosas bajas en ambos lados. El 28 de febrero se firma la Declaración de Montevideo, poniendo fin al conflicto armado. 


\section{Imaginarios}

Terminado el conflicto, empiezan dos nuevos procesos, la interpretación de lo sucedido y el paso a las negociaciones diplomáticas.

La opinión pública ecuatoriana y las Fuerzas Armadas reconocen la Guerra del Cenepa, como la primera victoria del período republicano, condición para la paz: "la Gesta del Cenepa, la victoria militar que allanó el camino para suscribir un acuerdo de paz con el Perú, cerrando así una herida abierta desde el proceso de independencia de la América del Sur." (Academia Nacional de Historia Militar del Ecuador 2020, 7)

Las negociaciones se dan en el marco del Protocolo de Río de Janeiro y logran un resultado clave: el Perú acepta la delimitación de la zona del conflicto, más allá del discurso de la tradición expansionista, que llegó a plantear que se debía llevar la frontera hasta la Cordillera de los Andes. El Ecuador, de su lado, renuncia al reclamo de las fronteras basado en la nulidad del Tratado de Río, acepta su vigencia como base para la delimitación de la zona en conflicto, cerrar las fronteras territoriales y finalizar el relato de la "herida abierta".

La Guerra del Alto Cenepa cierra un ciclo de la historia del Estado-nación, la delimitación tardía y definitiva de sus fronteras territoriales, bajo un hecho que es celebrado como victorioso.

\section{Los cambios}

La Guerra del Cenepa se da a destiempo, en el contexto de un nuevo ordenamiento mundial, a partir de la implosión de la Unión Soviética y la Caída del Muro de Berlín en la coyuntura del 1989-1991.

El cambio político fundamental, desde fines del siglo pasado, es el debilitamiento de los Estados-nacionales. "El Estado fue degradándose desde la categoría de motor más poderoso de bienestar universal a la de obstáculo más detestable, pérfido y molesto para el progreso económico. (...) En la actualidad, (...) el Estado se ha visto expropiado de una parte considerable (y creciente) de su antaño genuino o presunto poder (para hacer cosas), del que se han apropiado fuerzas supraestatales (globales) que operan en un «espacio de flujos» (Manuel Castells dixit) fuera de todo control político, mientras que el alcance efectivo de las agencias y los organismos políticos existentes no ha logrado ir más allá de las fronteras estatales." (Bauman y Bordoni, Estado de crisis 2016, 14 y 16)

El Estado nacional sufre un doble asedio: por arri$\mathrm{ba}$, el poder supranacional, articulado en torno a la alianza competitiva Estados centrales-Organismos multilaterales-Transnacionales; por abajo, las fracturas desde el descontento y la movilización social.
La licuefacción de las fronteras económicas por el mercado global y el predominio de las transnacionales, como poderes sin territorios, estuvo precedida por una modificación cultural profunda que minó las bases sólidas de la sociedad tradicional. El camino seguido por la modernidad fue la separación del individuo del seno de la naturaleza y la comunidad, mediante un proceso de desacralización y racionalización, que fue devorando los sucesivos espacios, niveles, instancias, para proclamar el dominio humanista antropocéntrico. Hoy la disolución afecta al propio individuo, en una dimensión post-humanista, y a las relaciones interindividuales, hasta crear un espacio autocentrado en el solipsismo del consumo, el éxito y la competencia. Actualmente, las relaciones parten de la fuga ante el otro; no se trata siquiera del dominio directo como en el esclavismo o en el capitalismo productivo; es la disolución de la propia relación en la suplantación mediadora de la inteligencia artificial, de las redes sociales, de la imagen virtual. El poder se presenta como una microfísica del biopoder, la vida es el objeto y el medio.

En el plano político, la nación imaginada, el Estado territorial y la política se disuelven. "El poder se ha vuelto extraterritorial, y ya no está atado, ni siquiera detenido, por la resistencia del espacio. (...) El poder puede moverse con la velocidad de la señal electrónica." (Bauman, Modernidad líquida 2004, 16). El resultado es la porosidad de las fronteras territoriales de los Estados-nacionales. Surgen nuevos fenómenos que trascienden las fronteras físicas, las migraciones, las mafias del tráfico de drogas, de armas, de personas, entrecruzados con la movilidad del capital financiero-especulativo. La propia naturaleza y objetivos de las guerras cambian: "ya no la conquista de un nuevo territorio, sino la demolición de los muros que impedían los flujos de los nuevos poderes globales fluidos. (...) Para que el poder fluya, el mundo debe estar libre de trabas, barreras, fronteras fortificadas y controles. Cualquier trama densa de nexos y relaciones sociales, y particularmente una red estrecha con base territorial, implica un obstáculo que debe ser eliminado." (Bauman, Modernidad líquida 2004, 17)

Aunque hay que tomar en cuenta, como muestra la emergencia de los nuevos Muros en las fronteras Norte-Sur, que estamos ante una globalización trunca y polarizante, los libres flujos de los capitales y las mercancías chocan con los controles y expulsiones de las olas de migrantes indeseados, "los mercados de productos y de capital tienden a ser mundializados. Mientras que los mercados de trabajo permanecen segmentados." (Amin 1997, 17)

La "Estrategia de Seguridad Nacional de Compromiso y Ampliación", emitida por el Gobierno de Clinton en 1994, en referencia a Latinoamérica, "resalta las mejores condiciones de seguridad obtenidas por la resolución de las tensiones fronterizas, el control de las insurgencias y la contención de las presiones para la proliferación de armas, así como el triunfo sin prece- 
dentes de la democracia y de la economía de mercado." (Academia Nacional de Historia Militar del Ecuador 2020, 13)

La Guerra del Cenepa, después del desenlace del enfrentamiento entre dos Estados-nacionales, pasa a la dimensión global. En la mesa de negociaciones impera la razón global del poder y del capital, la necesidad de derribar muros para el flujo libre del mercado de mercancías y capitales.

El Acta de Brasilia, firmada por los Presidentes de los dos países, el 26 de octubre de 1998, después de la aprobación de los Congresos, finiquita el largo conflicto limítrofe, con la demarcación de los 78 kilómetros en conflicto. El símbolo de la desterritorialización está en la definición del estatus de Tiwintza, el trofeo reclamado por los dos lados: el Acta reconoce la soberanía de Perú, pero deja un kilómetro cuadrado para la ocupación simbólica del Ecuador.

Esta ubicación de la Guerra del Cenepa en el cruce de dos tiempos fundamenta la ambigüedad de la memoria del acontecimiento: el festejo de la victoria y la racionalización pesarosa del Acuerdo para la paz. Pie de Foto 84 en (Vasco 2019, 153): "Área de combate defendida con valentía, , nos permitió recuperar el honor y dignidad nacional pero se perdió en la mesa de negociaciones."

\section{Las nuevas fronteras}

Y entonces se podría aplicar el aforismo, "cuando teníamos todas las respuestas, nos cambiaron las preguntas." La victoria del Cenepa cierra una larga historia de inconclusión de la identidad nacional y de un sentimiento de reveses y derrotas; y, al mismo tiempo, después del Acta de Paz, abre el paso a las nuevas fronteras. El paso de la Frontera Sur a la Frontera Norte opera un reordenamiento profundo de la ubicación geopolítica de nuestro país. Entramos en una nueva lógica, los temas territoriales dan paso a los nuevos conflictos difusos y complejos de las dinámicas globales.

Este desplazamiento afecta profundamente a la identidad y la organización de las Fuerzas Armadas. Estructuradas para responder al conflicto de la soberanía territorial, encuentran dificultades para enfrentar los problemas de las nuevas soberanías y responder a las presiones del poder global. Se produce una crisis de identidad por partida doble, desde dinámicas internas y externas. Se produce una transición de la "guerra convencional" a las "guerras irregulares o híbridas", cuyo proceso de comprensión es muy complejo y mucho más la preparación de capacidades, destrezas, en nuevas planificaciones y escenarios.

Estamos en un tiempo de incertidumbres, el tiempo global antes de la transición, marcado por la decadencia de la modernidad capitalista-colonial, con semillas débiles de alternativas; un tiempo de paradojas económicas, ambientales, políticas, culturales. La paradoja de la guerra y la paz nos presenta el fracaso de la oferta de paz mundial después de la caída del Muro, y el agu- dizamiento de las guerras en las fronteras de conflictos complejos que combinan las disputas civilizatorias con la lucha por el control de los recursos estratégicos, especialmente los recursos energéticos y el agua.

El largo conflicto colombiano, iniciado con el asesinato de Eliecer Gaitán en 1949, entra a finales de los 90 en la fase del Plan Colombia. Presentado, inicialmente como un Plan asistencial con políticas sociales en las zonas en conflicto, a partir del 2000 se transforma en un Plan guerrerista para enfrentar a la narco-guerrilla, como la amenaza principal: "el tráfico de drogas ilícitas se mostraba como la fuente primaria del conflicto colombiano." El 73\% de la ayuda norteamericana se orienta al Ejército para incrementar las fuerzas "en las zonas de mayor presencia ofensiva de la guerrilla y los paramilitares, pero con especial prioridad en el sur del país, pues esta era la zona que presentaba la mayor cantidad de cultivos de uso ilícito." (Guevara 2015, 74 y 77)

Dentro de esta estrategia belicista se busca el involucramiento del Ecuador, en un juego de "yunque y martillo", para cercar a las fuerzas guerrilleras. La decisión principal del Ecuador fue no verse involucrado en un conflicto que no le correspondía; sin embargo, no se logra desarrollar una estrategia integral de paz.

La estrategia global para enfrentar al nuevo enemigo, el terrorismo y el narcotráfico, parte de la "segurización" de la política y del Estado. "La fractura entre defensa y seguridad fundamenta el desplazamiento institucional desde el papel central de las Fuerzas Armadas al papel principal de las fuerzas policiales, para combatir el terrorismo y el narcotráfico, articuladas verticalmente a los acuerdos globales y a la regencia de los organismos de inteligencia americanos, la CIA y la DEA. (...) La Fuerza Pública y, en particular, las Fuerzas Armadas, están en un profundo proceso de cambios, a nivel local y mundial. En el centro está la redefinición del "monopolio de la violencia física legítima", no sólo dentro de un territorio, sino a nivel global. (Echeverría 2013)" (Saltos, Genealogía y modernización de las Fuerzas Armadas en Ecuador 2017, 58 y 59)

En medio del clima optimista del "fin de la historia", a partir de 1994, la estrategia norteamericana privilegia en el Continente, la incorporación económica al modelo de "mercado libre", primero mediante el impulso del ALCA (Área de Libre Comercio de las Américas), y, luego, ante el fracaso de la estrategia continental en 2003, por la resistencia encabezada por los "gobiernos progresistas", mediante Tratados de Libre Comercio bilaterales.

Paralelamente, para la readecuación geopolítica a las nuevas condiciones post-guerra fría y la expansión de la democracia, el dispositivo principal es la aprobación de los Libros Blancos de Defensa. "La OEA aprueba en 2002 un documento llamado 'Adopción de lineamientos sobre la elaboración de documentos sobre política y doctrinas nacionales de defensa"” (Barrachina 2008) 
Un cambio clave se opera a raíz de los atentados de las Torres Gemelas en el 11S. Afecta fundamentalmente al carácter de la soberanía, que se transforma de característica constitutiva de los Estados-nacionales, a capacidad como resultado de la correlación de fuerzas del poder mundial.

Este viraje se expresa en la Doctrina de Seguridad Nacional expedida por la Administración Bush (Bush 2002): modifica las bases espacio-temporales de las estrategias político-militares. En referencia al tiempo, consagra la doctrina de la guerra preventiva como el eje de la nueva Ley de Seguridad Nacional. En el espacio, establece una nueva división del mundo: clasifica los países en países fuertes, los que tienen capacidad de enfrentar las amenazas globales, especialmente el terrorismo y el narcotráfico; países débiles, que necesitan el tutelaje de los gobiernos fuertes y en particular de los Estados Unidos que tienen el destino manifiesto de proteger la paz y la democracia en el mundo; y los países basura, el "eje del mal", que impulsan el terrorismo y el narcotráfico.

En nuestro país se presentan dos cauces de respuesta: "El caso de Ecuador es significativo por la rapidez con que vivió el proceso de elaboración de libro. Iniciado oficialmente en mayo de 2002, (...) se publicó en diciembre de ese mismo año. (...) En este documento se interpreta el concepto de la multidimensionalidad de las amenazas ampliamente, señalándose que esta nueva realidad justifica el que los ejércitos deban ser capaces de abordar muchos de los aspectos que afectan a la seguridad de la nación y que en el contexto ecuatoriano no pueden ser desarrolladas más eficientemente por otras agencias gubernamentales." (Barrachina 2008). Esta línea se sigue en la administración de Lucio Gutiérrez; se aborda la reelaboración del Libro Blanco de Defensa, en una adecuación de la defensa y la seguridad a las concepciones sobre las nuevas amenazas globales.

En la Asamblea Constituyente de 2008 se introduce un cauce diferente: se instituye una concepción ampliada de la seguridad y se busca diferenciarla de la defensa, como el ámbito que corresponde a las Fuerzas Armadas. "En la Constitución del 2008 se busca la salida a través de la superposición de diversas formas, campos, territorios de soberanía. Soberanía popular (Art 1.), soberanía territorial (Arts. 4 y 158), soberanía nacional y globalización (Arts. 5 y 416), soberanía regional (Art. 423), soberanía de los pueblos (Arts. 57 y 398), soberanía económica, alimentaria y energética (Arts. 281, 384 y 304).” (Saltos, Genealogía y modernización de las Fuerzas Armadas en Ecuador 2017)

"En la Constitución del 2008 se produce la disgregación de la Fuerza Pública en dos cuerpos separados: Las Fuerzas Armadas y la Policía Nacional." Respecto a las Fuerzas Armadas, "cuatro cambios: la concentración de la misión fundamental de las Fuerzas Armadas en "la defensa de la soberanía y la integridad territorial", eliminando cualquier mención como defensoras de la democracia. La caracterización como servidores públicos
(Art. 158). La sujeción al poder civil (Art. 159). La eliminación del soporte económico para la autonomía de las Fuerzas Armadas (Art. 162)." (Saltos, Genealogía y modernización de las Fuerzas Armadas en Ecuador 2017)

Ninguna de estas vías permite resolver la nueva identidad y papel de las Fuerzas Armadas, en el marco de la democracia y de los cambios globales. Todavía durante la crisis de inestabilidad política en los 90, las Fuerzas Armadas pueden presentarse como "garantes de la democracia". Progresivamente van perdiendo sus puntos de referencia, incluso en la Frontera Norte, para garantizar una estrategia autónoma.

Los acontecimientos por el secuestro y asesinato de tres periodistas de El Comercio, el 26 de marzo de 2018, develan el problema de la Frontera: el vacío de los Estados en los dos lados, con la agudización de diversas formas de violencia y el control del territorio por fuerzas irregulares. El Ecuador carece de una estrategia orgánica para responder a los nuevos problemas. La ambigüedad entre una estrategia de negociación, exigida por diversos sectores sociales y la Iglesia, y la incorporación a la estrategia belicista de Colombia-Estados Unidos, termina por cobrar las vidas de los secuestrados. El desenlace de los hechos deja abierta la puerta para la inclinación a una salida de guerra, mientras el discurso de la paz se queda en palabras y promesas de la atención a las poblaciones y los territorios limítrofes.

\section{El asedio desde abajo}

El Estado-nacional sufre también presiones y asedios desde abajo. La desproporción entre las demandas de la sociedad y las exigencias transnacionales ante la reducida capacidad de respuesta de los gobiernos y los Estados de crisis, terminan por afectar no sólo a la legitimidad de las representaciones, sino a la propia institucionalidad estatal y a la vigencia de la democracia.

En nuestro país, también desde abajo surgen disputas en torno a la superposición de soberanías, sobre todo en los territorios afectados por la explotación minera y la acumulación rentista. "La relación entre la soberanía nacional y la soberanía de los pueblos indígenas se ha convertido en la frontera principal de los conflictos entre el Estado y los actores sociales, con presencia de nuevas formas de autoritarismo, juridización y criminalización de la lucha social, sobre todo en la resistencia al extractivismo." (Saltos, Genealogía y modernización de las Fuerzas Armadas en Ecuador 2017)

La resistencia de los pueblos indígenas, con el respaldo de sectores sociales, cuestiona el carácter uninacional del Estado y abre cauces a la visión del Estado plurinacional. La Constitución del 2008 expresa el impase de este problema: reconoce formalmente el carácter plurinacional del Estado, pero desactiva las formas de ejercerlo, sobre todo en el ejercicio de diferentes niveles de soberanía. En cada punto del conflicto, el monopolio de la violencia física legitimada entra en cuestionamiento. 
Los acontecimientos de octubre 2019 se presentan como un punto de ruptura en el funcionamiento del Estado. El símbolo es el Decreto 883, pero el problema es el modelo neoliberal, no sólo económico, sino ideológico, y el funcionamiento de la democracia liberal-representativa.

El punto de conflicto es el cruce de diversas formas de violencia: la irrupción de actos de violencia "divina" (Benjamin 2001) como un "estallido social" contra los varios rostros de la desigualdad y la injusticia, la rebelión de las masas que acuden a la democracia de la calle para expresar su descontento ante la incapacidad de las instancias democráticas representativas para resolver pacíficamente las demandas sociales. La presencia de violencias instrumentales desde dos polos de poder: la estrategia de desestabilización de sectores vinculados al correismo; y el ataque violento del Gobierno a las movilizaciones masivas, bajo el argumento, en un juego de espejos, de enfrentar la desestabilización. El acontecimiento radica en la irrupción de la "autonomía" de la movilización social ante los polos de poder y sus proyectos, tanto el modelo de libre mercado, como el modelo estatista. (Saltos y otros, Octubre 2020)

Se opera el paso desde los dispositivos represivos del período de Correa, centrados en el control preventivo y el descabezamiento de las movilizaciones, bajo una estrategia disciplinaria y la predominancia de los aparatos de seguridad e inteligencia; a las nuevas formas de represión masiva, basados en las doctrinas israelitas y las variaciones chilenas sobre el control de pueblos y masas, que tienen como actores principales a las fuerzas policiales.

\section{Después de 25 años: la disyuntiva}

$\mathrm{Y}$ en medio de estas disputas, regresa la pregunta sobre el papel de las Fuerzas Armadas ante los conflictos sociales internos y ante los cambios globales.

Los discursos de los voceros oficiales del Gobierno de Lenin Moreno, tanto de la Ministra de Gobierno como del Ministro de Defensa, apuntan al alineamiento con el retorno a una nueva versión de la Doctrina de la Seguridad Nacional que señala como la amenaza principal la presencia de fuerzas subversivas internas, identificadas con la movilización social indígena. Esta visión entra en contradicción con la tradición civilista de las Fuerzas Armadas que, sobre todo, a partir de la alianza estratégica establecida en la preparación y ejecución de la Guerra del Cenepa, fundamentaron la visión de que "las Fuerzas Armadas jamás dirigirán las armas contra su propio pueblo."

El reto democrático para las Fuerzas Armadas se presenta como una pregunta sobre su propia identidad hacia adentro y hacia afuera.

La memoria de la victoria del Cenepa no puede quedarse en la celebración. El pasado regresa en espiral al presente, para poder encontrar pistas para las respuestas actuales y la proyección al futuro. El primer paso es un tiempo de reflexión, para construir una doctrina y una estrategia propia, a partir de los aportes de las ciencias en el mundo y la originalidad de nuestro país y nuestra América; reconocer a las Fuerzas Armadas, no sólo como una institución estatal, sino como una institución asentada en la sociedad.

\section{REFERENCIAS}

[1] Academia Nacional de Historia Militar del Ecuador. La Guerra del Cenepa. 25 años. Quito: Instituto Geográfico Militar, 2020.

[2] Accossatto, Romina. «Colonialismo interno y memoria colectiva. Aportes de Silvia Rivera Cusicanqui al estudio de los movimientos sociales y las identificaciones políticas.» Economía y Sociedad [en linea]. XXI, n ${ }^{\circ} 36$ (2017): 167-181.

[3] Amin, Samir. «Capitalismo, imperialismo, mundialización.» En Resistencias mundiales. De Seattle a Porto Alegre, de José Seoane, Emilio Taddei (compiladores), 15-29. Buenos Aires: CLACSO, 1997.

[4] Báez, René. «La quimera de la modernización.» En Ecuador: pasado y presente, de René Báez y otros, 169 223. Quito: LIBRESA, 2003.

[5] Barrachina, Carlos. Programa interno de medidas de confianza mutua: los Libros Blancos en América Latina bajo una perspectiva comparada. Vols. III, Estudios comparados, de La administración de la defensa en América Latina, de Sepúlveda y S Alda (editores), 423-446. Madrid: IUGM, 2008.
[6] Bauman, Zygmunt. Modernidad líquida. Tercera Reimpresión. Argentina: Fondo de Cultura Económica, 2004.

[7] Bauman, Zygmunt, y Carlo Bordoni. Estado de crisis. Primera edición. Barcelona: PAIDÓS, 2016.

[8] Benjamin, Walter. Para una crítica de la violencia y otros ensayos. Madrid: Taurus, 2001.

[9] Bush, George W. «Estrategia de Seguridad Nacional.» 17 de Septiembre de 2002. http://usinfo. state.gov/espanol/terror/02093001. htm\#eight.

[10] Echeverría, Bolívar. «Violencia y modernidad.» 7 de Junio de 2013. http://marxismocritico. com/2013/06/07/violencia-ymodernidad/ (último acceso: 30 de Junio de 2015).

[11] Foucault, Michel. «Nietzsche, la généalogie, 1`histoire .» En Dits et écrits. 1954 - 1988. II 1970 - 1975, de Michel Foucault, 136-156. París: Éditions Gallimard, 1994.
[12] Guevara, Juan. «El Plan Colombia o el desarrollo como seguridad.» Revista Colombiana de Sociología XXXVIII, $n^{\circ} 1$ (2015): 63-82.

[13]

[14] Moncayo, Paco. «La guerra vista por el jefe.» 27 de Mayo de 1995. http:// archive.is/CVSY (último acceso: 20 de Enero de 2020).

[15] Saltos, Napoleón. «Genealogía y modernización de las Fuerzas Armadas en Ecuador.» Ciencia Política XII, no 24 (2017): 51-75.

[16] Saltos, Napoleón, y otros. Octubre. Quito: El árbol de papel, 2020.

[17] Silva, Érika. Identidad nacional y poder. Segunda edición. Quito: Abya Yala, 2005.

[18] Vasco, Carlos. La logística de la Guerra del Cenepa. Quito: Editorial Politécnica EdiEspe, 2019.

[19] Zavaleta, René. La formación de la conciencia nacional. La Paz: Los amigos del libro, 1990. 